\title{
The Arbuscular Mycorrhizal Fungi's diversity in Fabaceous trees species of Northeastern Thailand
}

\author{
PENPITCHA CHOOSA-NGA, UTHAIWAN SANGWANIT, THARNRAT KAEWGRAJANG \\ Department of Forest Biology, Faculty of Forestry, Kasetsart University. 50 Ngamwongwan Rd, Lat Yao, Chatuchak, Bangkok 10900, Thailand. \\ Tel. +66-257-90176, Fax. +66-294-28107 `email: ffortrk@ku.ac.th
}

Manuscript received: 11 January 2019. Revision accepted: 18 January 2019.

\begin{abstract}
Choosa-Nga P, Sangwanit U, Kaewgrajang T. 2019. The Arbuscular Mycorrhizal Fungi's diversity in Fabaceous trees species of Northeastern Thailand. Biodiversitas 20: 405-412. The species diversity of arbuscular mycorrhizal (AM) fungi, found in three Fabaceous tree species, namely, Dalbergia cochinchinensis, Pterocarpus macrocarpus and Xylia xylocarpa, was studied. Sixty rhizosphere soil samples were collected from the tree species plantations, and AM fungal spores were extracted and identified using their morphological characteristics. The spore density and species diversity of the fungi associated with these Fabaceous tree species was assessed. The 11 AM fungi morphospecies identified were Acaulospora (3 species), Glomus (6 species), Sclerocystis (1 species) and Scutellospora (1 species). Meanwhile, three species remained unidentified, which Unknown sp.2 was frequently found in all the three of plantations. The Shannon-Weiner diversity index of the fungal species ranged from 1.40 to 1.88 , while the Evenness index ranged from 0.58 to 0.76 . The diversity and Evenness index was the highest in the $D$. cochinchinensis plantation and lowest in the $X$. xylocarpa plantation. These differences may be due to differences in soil characteristics, including moisture, $\%$ organic matter, and nutrient composition. The species composition of AM fungi in the P. macrocarpus plantation was not similar with the $D$. cochinchinensis and X. xylocarpa plantations. It was indicated that different plant species were hosts to different AM fungal communities. Therefore, further studies are required to select the appropriate AM fungal species which have a positive effect on the growth of the three Fabaceous species when we would like to do the inoculating programs.
\end{abstract}

Keywords: Dalbergia cochinchinensis, endomycorrhiza, mycorrhiza, Pterocarpus macrocarpus, Xylia xylocarpa

Abbreviations: AM: Arbuscular Mycorrhiza, AMF: AM fungi, DC: Dalbergia cochinchinensis, PM: Pterocarpus macrocarpus, XX: Xylia xylocarpa, SD: spore density, RA: relative abundance, OM: organic matter, P: phosphorous, N: nitrogen, K: potassium

\section{INTRODUCTION}

Arbuscular mycorrhiza (AM) is a symbiotic association between a fungus and the roots of a plant. The plant growth is enhanced by such mycorrhizal interactions with an increased access to soil resources, including the ability to trap water and alleviate nutrient stress by obtaining greater amounts of phosphorous $(\mathrm{P})$, nitrogen $(\mathrm{N})$ and potassium (K) (Smith and Read 2008; Lee et al. 2013; Cardoso et al. 2017). Other advantages of this symbiosis is increased resistance to root pathogens (Pozo et al. 2010), tolerance to environmental stresses such as salinity and drought (Hameed et al. 2014; Latef et al. 2016), and heavy metal contamination (Upadhyaya et al. 2010). AM fungi (AMF) are one of the most abundant organisms in the soil rhizosphere and are found in a wide range of host plants with ca. $70-90 \%$ of terrestrial plant species, from bryophytes to tracheophytes (Brundrett 2009). Therefore, their species diversity is low and they have indicated a lack of host specificity (Lee et al. 2013). Only 240 species of AMF exist, which belong to the phylum Glomeromycota, contain three classes, five orders, 14 families and 29 genera (Morton and Msiska 2010; Oehl et al. 2011; Krüger et al. 2012). In the tropical region, the AM plays an important role in both the natural and agricultural ecosystems, when compared with the other types of mycorrhizae (Cardoso et al. 2017). However, all the studies related to AMF have focused on temperate ecosystems. Consequently, very little is known about the interaction between the fungi and host plants in extremely diverse communities such as tropical forests (Kiers et al. 2000; Husband et al. 2002). Previous studies conducted in tropical forests have indicated that the diversity of AMF is low and has no specific to their host plants. Marionho et al. (2018) reported 228 AMF in tropical forests, distributed in three classes, five orders, 14 families, and 35 genera. Among the AM fungal community, Acaulospora and Glomus were the dominant genera in tropical rhizosphere soils (Zhao et al. 2003; Marionho et al. 2018).

Many native fabaceous tree species in tropical forests are sources of the most valuable timber in the world. As a result, over the years, their numbers have been gradually declining due to their feeling for the valuable timber. The wood derived from the trees has been used traditionally for carving, making musical instruments, and luxury furniture in South America, Africa, and South East Asia (Jenkins et al. 2012). International trade of various species in the Fabaceae family has been increasing steadily and more and more species are being traded internationally, most of which is done in the black markets (CITES COP17 Prop.55). The Fabaceous trees species have a relatively low regeneration rate and slow growth in natural ecosystem. 
Consequently, a proper balance of their populations in the conservation areas is not met leading to a gradual decline in numbers. Many shrubs and herbaceous plant species in Fabaceae family have been examined for the presence and diversity of AMF, while only some trees species in the family, i.e., Acacia auriculiformis, A. mangium, Albizia saman Dalbergia sissoo, Paraserianthes falcataria, and Pongamia pinnata, have been reported to have an association with the AM fungal species (Weravart 2003; Dhar and Mridha 2006; Wulandari et al. 2016; Ponpandian and Rose 2017). Dhar and Mridha (2006) showed that the dominant AMF found in the plants of the family Fabaceae was from the Glomus genus, while Ponpandian and Rose (2017) reported that Acaurospora was also abundant in the rhizosphere of the soils of Pongamia pinnata (Fabaceae). Currently, there is limited knowledge on AM fungal species in the rhizosphere of the soils of tropical forest tree species, especially for species with high economic value like Dalbergia cochinchinensis (DC), Pterocarpus macrocarpus (PM), and Xylia xylocarpa (XX). Therefore, the aim of this study was to investigate the species identity, richness, and diversity of AMF in the rhizospheres of the soils of D. cochinchinensis, P. Macrocarpus, and $X$. xylocarpa. Moreover, we aimed to determine the differences in the AMF communities found in the three plant species.

\section{MATERIALS AND METHODS}

\section{Sampling sites}

The sampling site was located in the Sakaerat silvicultural research station, Nakhon Ratchasima province, northeastern Thailand. The station is maintained by the Royal forest department (Figure 1). The Phu Luang forest reserve is located on the eastern side of the station with a total area of around 7,458 ha including the station area. The area around the station was covered with a dry evergreen and dry dipterocarp forest until the 1950s, until it was encroached by the local farmers and converted into agricultural land. Since 1967 , over 2,000 ha (28\% of total area) of the area, which was abandoned and covered with tall grasses, has been under a re-afforestation project with native and exotic fast-growing tree species been planted (Kamo et al. 2002; Visaratana et al. 2008).

\section{Soil sampling}

The rhizosphere soils from the three Fabaceous plantations as treatments, namely Dalbergia cochinchinensis (DC) plantation; Pterocarpus macrocarpus (PM) plantation; Xylia xylocarpa (XX) plantation, were collected during the months from June to September 2016. Twenty trees were randomly selected from each plantation. DC and PM plantation's age is 30-year old, while XX plantation is 11-year old. Each plantation has total area 1.6 ha and is planted with spacing $2 \times 4 \mathrm{~m}$. One soil core $(5 \mathrm{~cm}$ in diameter, $10 \mathrm{~cm}$ in depth), located $1 \mathrm{~m}$ away from the base of each tree, was collected and 20 soil cores were collected from each plantation. In total, 60 soil samples were collected, placed in polyethylene bags, and transported to the laboratory, where they were stored at $4^{\circ} \mathrm{C}$ prior to spore extraction. Moreover, five disturbed soils samples (300-500 g/sample) were randomly collected from each plantation. These soil samples were analyzed to determine the soil properties, which included $\mathrm{pH}$, soil moisture, organic matter, total $\mathrm{N}$, available $\mathrm{P}$, and exchangeable $\mathrm{K}$ content.

\section{AM fungal spore extraction and identification}

Spores were isolated from a $4 \mathrm{~g}$ subsample obtained from each soil sample using the modified wet sieving method (Brundrett et al. 1996) and sucrose centrifugation (Daniels and Skipper 1982). Each subsample was first placed in a bucket containing $2 \mathrm{~L}$ of tap water, swirled, and the resulting soil suspension was then passed through three nested sieves, with an aperture of size 150, 75, and $45 \mu \mathrm{m}$. The material remaining on each sieve was transferred to a separate tube for each sieve, containing 50\% sucrose gradient. Then each tube was centrifuged at 4,000 rpm for 5 mins. The supernatant was transferred to a new test tube containing 50\% sucrose gradient and centrifuged at 3,000 $\mathrm{rpm}$ for $1 \mathrm{~min}$. It was then poured onto a sterile filter paper and rinsed with sterile distilled water several times and the spores remaining on the filter paper were inspected under a stereomicroscope (Ziezz Stemi 508).

\section{Species identification}

All the spores were isolated, mounted on a slide with polyvinyl alcohol-lactic acid-glycerol (PVLG), for the identification of the AM fungal species. The AM fungal spores were distinguished for their morphotype by observing the macroscopic features under a compound microscope (Zeiss Axioskop 40) from 10-100X magnification. These included size, color, hyphal attachment, shape, type, and the number of spore walls. The species were identified using the manual recommended for the identification of Vesicular-arbuscular (VA) mycorrhizal fungi of Schenck and Perez (1988). Furthermore, online databases of species description at the West Virginia University, USA (http: //invam.caf.wvu.edu) and the Department of Plant Pathology, University of Agriculture in Szczecin, Poland (http: //www.agro.ar.szczecin.pl/ jblaszkowski/), were used to identify the AM species.

\section{Data analysis}

Soil characteristics at the three plantations were compared using one-way analysis of variance (ANOVA). Additionally, the number of AM species was determined by directly counting the number of fungal species per soil sample. The spore density (SD) of the AM fungal species was defined as the number of spores in $100 \mathrm{~g}$ of soil sample. It was assessed using a one-way ANOVA to compare the spore density in different plantations. All the statistical analyses were performed using the R Statistical software (Version Ri386.3.5.1). 

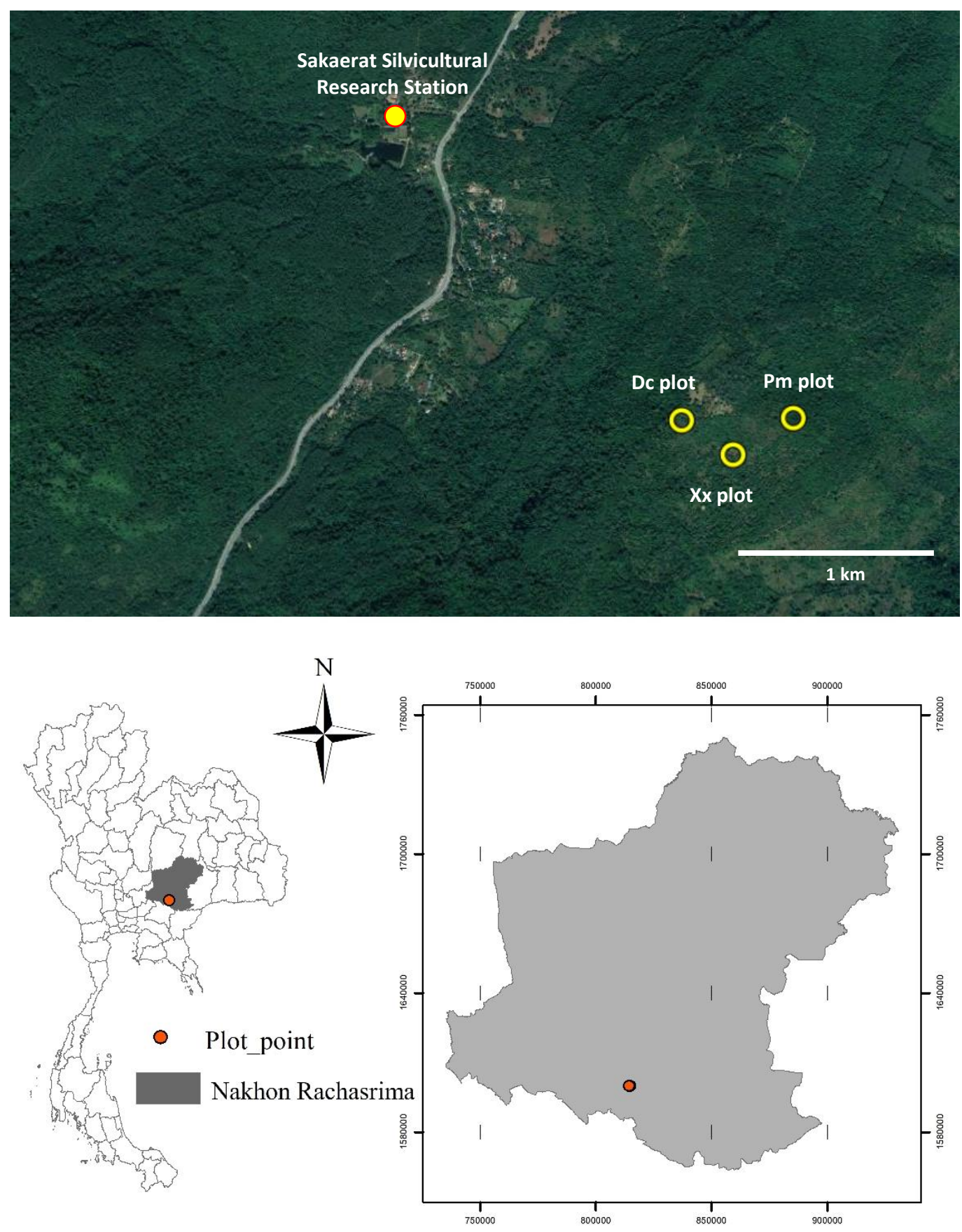

Figure 1. Location of the Sakaerat Silvicultural Research Station, Nakhon Ratchasima province, Thailand indicating the sampling sites. Dc plot: Dalbergia cochinchinensis plantation, Pm plot: Pterocarpus macrocarpus plantation, Xx plot: Xylia xylocarpa plantation

Relative abundance (RA) was defined as the percentage number of spore of a species divided by the total spores observed. The dominant AM fungal species was determined by SD and RA. The Shannon-Weiner's index $\left(H^{\prime}\right)$ (Magurran 1988) was chosen to measure the fungal species diversity in different plantations using the equation $H^{\prime}=-\Sigma p_{i}(\ln p i)$, where $p i$ is the ratio of the number of spores in the $i$ th species to the total number of spores, $i=1$, $2,3, \ldots ., n$, and the summation was done over the total number of species $n$. In addition, the Pielou's evenness index (E) (Pielou 1966) was evaluated using the equation $\mathrm{E}$ $=H^{\prime} / \ln \mathrm{S}$, where $H^{\prime}$ is the number derived from the Shannon-Weiner's index and $S$ is the total number of species in a sample, across all samples in a dataset. Moreover, the two-way clustering analysis, with Sorensen (Bray-Curtis) distance was implemented in PC-ORD version 6.08 (Peck 2010) to classify group of AM species. 


\section{RESULTS AND DISCUSSION}

\section{Soil characteristics}

The soil $\mathrm{pH}$ ranged from 4.07 to 4.48 , organic matter $(\mathrm{OM})$ between 1.8 to $6.76 \%, \mathrm{~N}$ between 0.10 to $0.21 \%, \mathrm{P}$ between 5.77 to $15.72 \mathrm{mg} / \mathrm{kg}$, K between 32.60 to 136.24 $\mathrm{mg} / \mathrm{kg}$ and soil moisture content between $7-23 \%$, across the plantations (Table 1). It indicated that the soil has strong acid and contained moderate chemical properties. The soil characteristics were significantly different among the plantations $(P<0.05)$, except $\mathrm{pH}$ and the level of $\mathrm{P}$. DC plantation, had the highest soil moisture content, OM, and total $\mathrm{N}$, while all soil characteristics were the lowest in the $\mathrm{XX}$ plantation.

\section{AM species diversity}

Spore density, in the soil samples, ranged from 1125 to 9350 spores $100 \mathrm{~g}^{-1}$ soil (with a mean of $4156 \pm 2001$ spores). The spore density was not significantly different across plantations $(P>0.05)$. However, the maximum spore density was measured in the XX plantation $(4313 \pm 1646)$, while it was the lowest in the PM plantation $(4017 \pm 1970)$ (Figure 2).

Fourteen morphospecies of AMF, recovered from the 60 soil samples, were identified using their spore characteristic features. There were 3 species in Acaulospora, 6 species in Glomus, 1 species in Sclerocystis, 1 species in Scutellospora, and 3 unidentified species in the three plantations (Figure 3). There were 12, 13, and $11 \mathrm{AM}$ species found in the DC, PM and XX plantations, respectively. The Shannon-Weiner's index was the highest in the DC plantation $\left(H^{\prime}=1.8\right)$ and lowest in the $\mathrm{XX}$ plantation $\left(H^{\prime}=1.40\right)$. Similarly, E ranged from 0.58 to 0.76 , being the highest in the DC plantation and lowest in the XX plantation (Table 2).

\section{Two-way cluster analysis}

The similarity index based on two-way cluster analysis indicated to two clear clusters distinguished as Group 1, consisting of AM fungal communities in the rhizosphere soil of DC and XX plantation and Group 2, consisting of AM fungal communities in the rhizosphere soil of PM plantation (Figure 4). There were several dominant species in Group 1, such as Acaulospora sp.1 (Acau1), Acaulospora sp.3 (Acau3), G. aggregatum (Gloag), G. fasciculatum (Glocffa), G. pustulatum (Glocfpu), Glomus sp.1 (Glo1), S. pachycaulis (Sclpa), Acaulospora sp.2 (Acau2), Unknown sp.1 (Unk1), Unknown sp.2 (Unk2), and G. maculosum (Gloma). On the other hand, $G$. maculosum (Gloma), Unknown sp.3 (Unk3), Glomus sp.2 (Glo2) (Scusp), and Unknown sp.2 (Unk2) were dominant in the rhizosphere of Group 2. These AM fungal species were mostly found in Group 2 (XX plantation), except Unknown sp.2 (Unk2) and G. maculosum (Gloma), which were dominant in both the groups.

\section{AM fungal spore density and relative abundance}

The SD and RA of AM fungal species are shown in Table 3. The results indicate that the Unknown sp. 2 was the most dominated species in all three plantations $(\mathrm{RA}=34.2$ in DC; 51 in PM; 54.7 in XX), followed by Glomus maculosum (RA=18.4 in DC; 19.5 in PM; 9.6 in $\mathrm{XX}$ ), and Acaulospora sp.2 (RA=17.5 in DC; 14.3 in PM; 21.8 in $\mathrm{XX}$ ). There were some species which were rarely found in any of the plantations. Some AMF appeared only in the PM plantation, for e.g., Glomus sp.2 and Scutellospora sp. Moreover, Glomus fasciculatum was found in both DC and PM plantations and Sclerocystis pachycaulis was found in $\mathrm{DC}$ and $\mathrm{XX}$ plantations.

Table 1. Soil characteristics of the three Fabaceous tree plantations at Sakaerat silvicultural research station, Thailand

\begin{tabular}{llll}
\hline $\begin{array}{l}\text { Soil characteristics } \\
\text { (mean } \pm \text { SD) }\end{array}$ & \multicolumn{1}{c}{ DC } & \multicolumn{1}{c}{ PM } & \multicolumn{1}{c}{ XX } \\
\hline pH & $4.31 \mathrm{a} \pm 0.16$ & $4.16 \mathrm{a} \pm 0.09$ & $4.19 \mathrm{a} \pm 0.05$ \\
Soil moisture (\%) & $19.42 \mathrm{a} \pm 1.91$ & $17.53 \mathrm{a} \pm 1.43$ & $7.84 \mathrm{~b} \pm 1.38$ \\
OM $(\%)$ & $5.41 \mathrm{a} \pm 1.84$ & $2.52 \mathrm{~b} \pm 0.96$ & $1.78 \mathrm{~b} \pm 0.23$ \\
Total N (\%) & $0.20 \mathrm{a} \pm 0.02$ & $0.15 \mathrm{ab} \pm 0.03$ & $0.11 \mathrm{~b} \pm 0.02$ \\
Available P (mg/kg) & $8.48 \mathrm{a} \pm 2.35$ & $8.53 \mathrm{a} \pm 0.72$ & $10.10 \mathrm{a} \pm 4.87$ \\
Exchangeable K & $78.73 \mathrm{a} \pm 1.91$ & $107.65 \mathrm{a} \pm 27.33$ & $32.81 \mathrm{~b} \pm 0.22$ \\
(g/kg) & & & \\
\hline
\end{tabular}

Note: DC: Dalbergia cochinchinensis plantation; PM: Pterocarpus macrocarpus plantation; XX: Xylia xylocarpa plantation; SD : standard deviation; and means in row with similar letters ( $a, b, c)$ are not statistically significant $(\mathrm{P}>0.05)$.

Table 2 Total number of species (n), Shannon-Wiener's diversity index and $\mathrm{E}$ of AMF in the three Fabaceous tree plantations at Sakaerat silvicultural research station, Thailand

\begin{tabular}{llll}
\hline & DC & PM & XX \\
\hline Total number of species $(\mathrm{n})$ & 12 & 13 & 11 \\
Shannon-Wiener's Index $\left(H^{\prime}\right)$ & 1.88 & 1.49 & 1.40 \\
Evenness Index (E) & 0.76 & 0.58 & 0.59 \\
\hline Note: DC: Dalbergia & cochinchinensis & plantation; PM: \\
$\begin{array}{l}\text { Pterocarpus macrocarpus } \\
\text { plantation }\end{array}$ & plantation; XX: & Xylia & xylocarpa \\
& & &
\end{tabular}

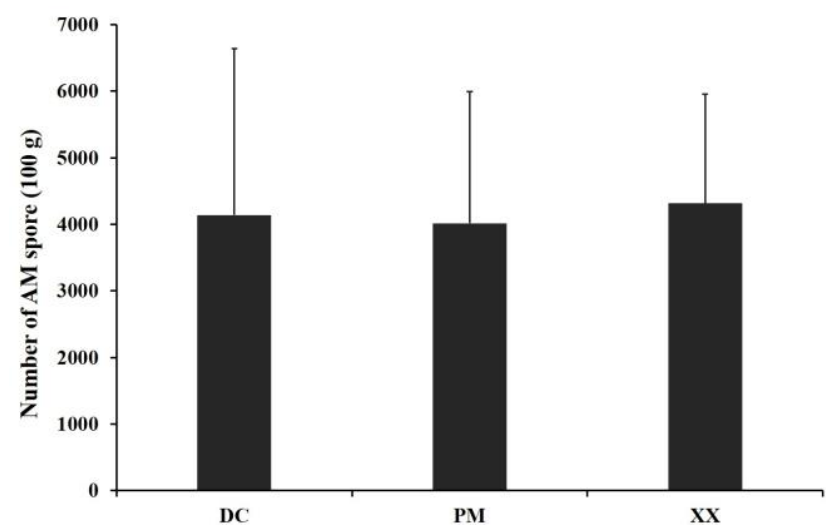

Figure 2 Spore density of AMF in the Sakaerat silvicultural research station, Thailand (black filled columns). DC: Dalbergia cochinchinensis plantation, PM: Pterocarpus macrocarpus plantation, XX: Xylia xylocarpa stand). The error bars indicate standard deviation (as obtained from Duncan's new multiple range test $(P>0.05)$ 


\section{Discussion}

Members of the Fabaceae plant family are known to have an AM symbiosis (Weravart 2003; Dhar and Mridha 2006; Washa et al. 2012). In this study, we firstly identified the species, richness, SD, and species composition of AMF in the rhizosphere soils of three important Fabaceous tree species, i.e., D. cochinchinensis, $P$. macrocarpus, and $X$. xylocarpa, growing in various plantations in northeastern Thailand (located in the Sakaerat silvicultural research station, Nakhon Ratchasrima Province).

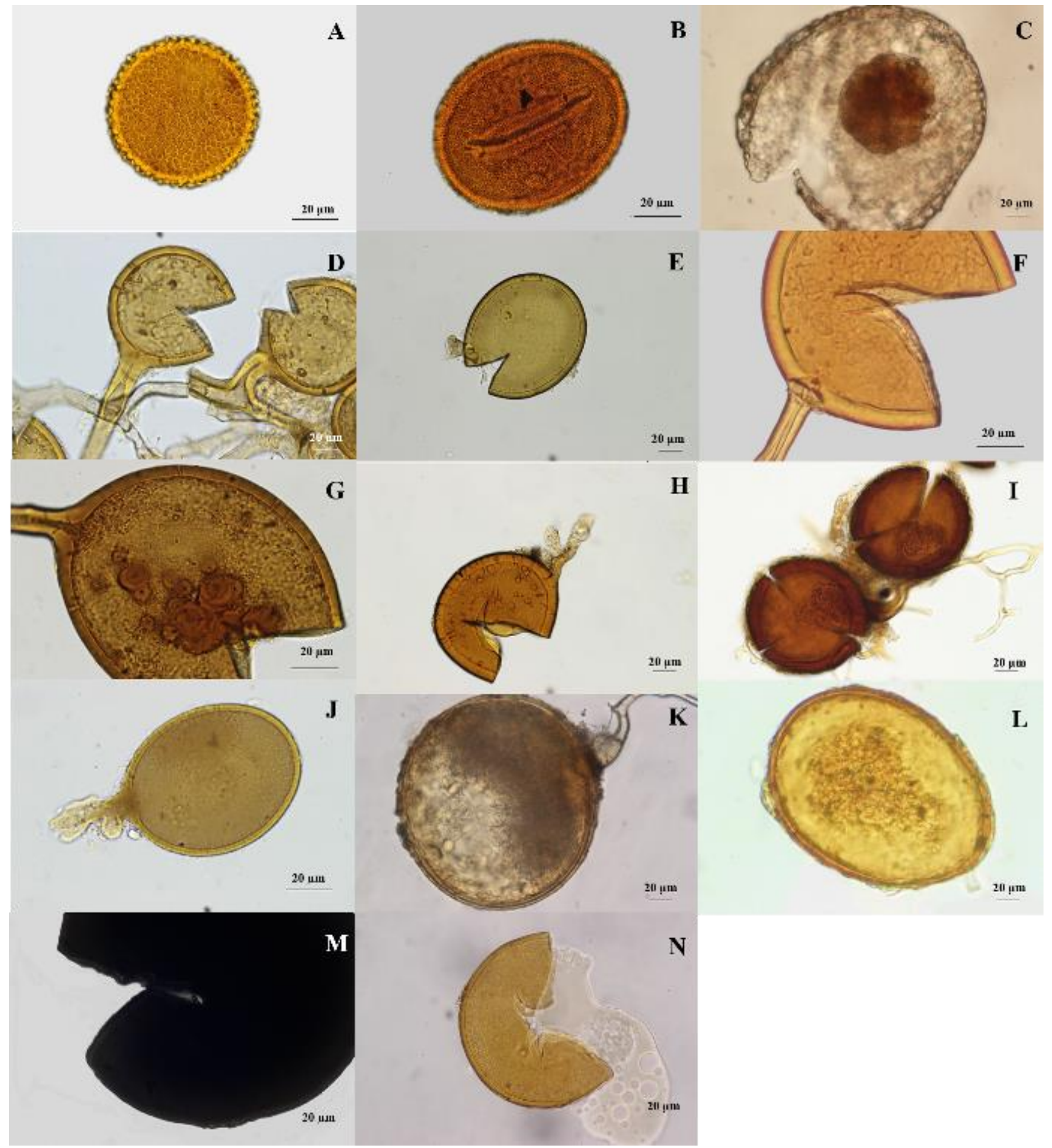

Figure 3. AMF found in plantations of D. cochinchinensis, P. macrocarpus and X. Xylocarpa. A. Acaulospora sp.1, B. Acaulospora sp.2, C. Acaulospora sp.3, D. Glomus aggregatum, E. Glomus fasciculatum, F. Glomus maculosum, G. Glomus pustulatum, H. Glomus sp.1, I. Glomus sp.2, J. Sclerocystis pachycaulis, K. Scutellospora sp.1, L. Unknown sp.1, M. Unknown sp.2, and N. Unknown sp.3 


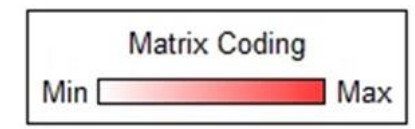

Information Remaining (\%)

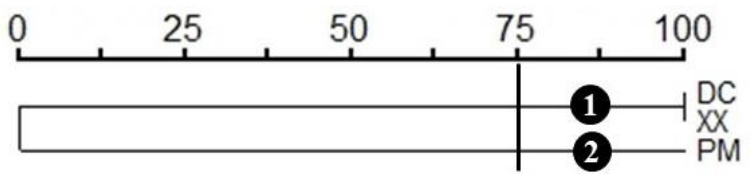

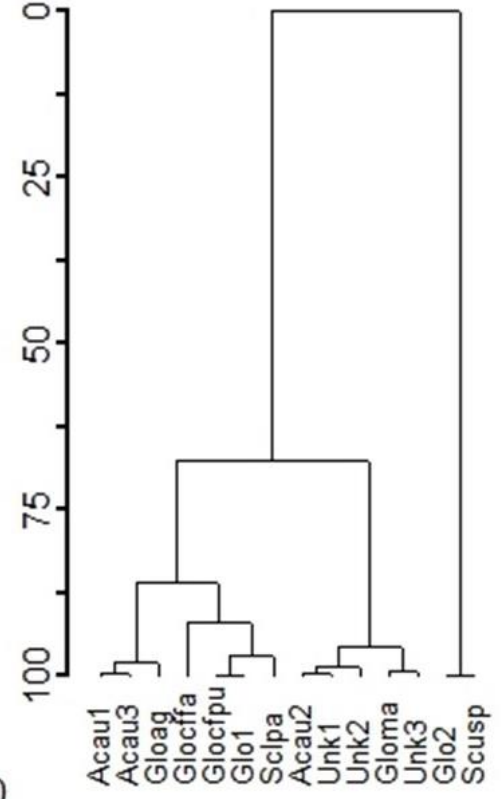

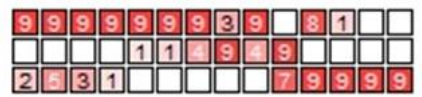

Figure 4. Cluster analysis of AMF in the three plantations. DC: Dalbergia cochinchinensis plantation; PM: Pterocarpus macrocarpus plantation; XX: Xylia xylocarpa plantation

Table 3 Spore density (SD) and relative abundance (RA) of AM fungal species in plantations at the Sakaerat silvicultural research station, Thailand

\begin{tabular}{|c|c|c|c|c|c|c|}
\hline \multirow{2}{*}{ AM fungal species } & \multicolumn{2}{|c|}{ DC } & \multicolumn{2}{|c|}{ PM } & \multicolumn{2}{|c|}{$\mathbf{X X}$} \\
\hline & SD & RA (\%) & SD & RA (\%) & SD & RA (\%) \\
\hline Acaulospora sp.1 & 323 & 7.8 & 178 & 4.4 & 133 & 3.1 \\
\hline Acaulospora sp.2* & 725 & 17.5 & 575 & 14.3 & 940 & 21.8 \\
\hline Acaulospora sp. 3 & 28 & 0.7 & 20 & 0.5 & 10 & 0.2 \\
\hline Glomus aggregatum N.C. Schenck \& G.S. Sm & 60 & 1.4 & 28 & 0.7 & 8 & 0.2 \\
\hline Glomus fasciculatum (Thaxter) Gerd. \& Trappe & 25 & 0.6 & 3 & 0.1 & - & - \\
\hline Glomus maculosum* D.D. Miller \& C. Walker & 760 & 18.4 & 783 & 19.5 & 413 & 9.6 \\
\hline Glomus pustulatum Koske, Friese, C. Walker \& Dalpé & 425 & 10.3 & 98 & 2.4 & 150 & 3.5 \\
\hline Glomus sp.1 & 75 & 1.8 & 15 & 0.4 & 30 & 0.7 \\
\hline Glomus sp.2 & - & - & 8 & 0.2 & - & - \\
\hline Scutellospora pachycaulis C.G. Wu \& Z.C. Chen & 40 & 1 & - & - & 20 & 0.5 \\
\hline Scutellospora sp. & - & - & 3 & 0.1 & - & - \\
\hline Unknown sp.1 & 135 & 3.3 & 110 & 2.7 & 128 & 3.0 \\
\hline Unknown sp.2* & 1415 & 34.2 & 2048 & 51 & 2358 & 54.7 \\
\hline Unknown sp.3 & 128 & 3.1 & 153 & 3.8 & 125 & 2.9 \\
\hline Total & 4138 & 100 & 4018 & 100 & 4313 & 100 \\
\hline
\end{tabular}

Note: DC: Dalbergia cochinchinensis plantation; PM: Pterocarpus macrocarpus plantation; XX: Xylia xylocarpa plantation; *: dominant species.

In a tropical rainforest, the SD of AMF is low, at the same time, being the most abundant, when comparing with the other organisms (Zhao et al. 2003). Additionally, Acaulospora and Glomus were the dominant genera of AM fungal community in tropical rhizosphere soils (Zhao et al. 2003; Marionho et al. 2018). In our study, a total number was 14 AMF species was observed. Four genera were isolated from the rhizosphere soils of different plantations. Glomus was found to be the dominant genera in terms of spore diversity and SD (Table 4). Moreover, our study indicated that G. maculosum G. pustulatum and Unknown sp.2 were frequently found and dominant in all three plantations. These results are similar with the previous study of Dhar and Mridha (2006), who reported that the major AMF in the rhizosphere of other Fabaceous tree species, such as Acacia auriculiformis, A. mangium, and Dalbergia sissoo, was Glomus. Weravart (2003) also reported that Glomus was the dominant genus among the 
27 AMF in the rhizosphere of A. mangium. Additionally, we found that Acaulospora was second most dominant genus following Glomus. Similar results were obtained by Ponpandian and Rose (2017), who reported 19 AMF species in the rhizosphere soils of Pongamia pinnata (Fabaceae) as well as Acaulospora, which was the predominant genus following Glomus. It was indicated that genus Acaulospora was found to be one of the dominant genera in other host species. Charoenpakdee et al. (2010) reported that Acaulospora was the major AMF found in the rhizosphere soils of physic nut (Jatropha curcas L.). Bever et al. (1996) and Hepper (1984) stated that Glomus and Acaulospora species grow in clusters, produce smaller-size of spores and sporulate more frequently, while other species like Gigaspora, Scutellospora, etc., sporulate singly. Therefore, a larger population of Glomus and Acaulospora species should have a higher chance to be detected in the rhizosphere soil.

In this study, the Shannon-Weiner's index and Evenness index were highest in the DC plantation and the lowest in XX plantation. The difference may be due to the nutrient composition of the soil. In our study, we observed that the soil physical properties were different in the three plantations. When we compared the soil physical properties among the three plantations, the XX plantation had the lowest soil moisture, OM, N and K content, but the highest $\mathrm{P}$ content. On the contrary, DC plantation had the highest level of soil moisture, OM, and N content, and the lowest $\mathrm{P}$ content. Visaratana et al. (2004) who studied litter production in the DC, PM and XX plantation at Sakaerat silvicultural research station (the same plantation with our sampling site), reported that the DC plantation was the highest in amount of litterfall, when was compared with the $\mathrm{PM}$ and $\mathrm{XX}$ plantations. Therefore, these results may be due to the amount of OM in the DC plantation was higher than the other two plantations. Additionally, owing to the older plantation age and closer crown canopy, the soil moisture of the DC plantation was higher the XX plantation. Previously, Nongkling and Kayang (2017) had indicated that the OM, soil moisture, and nutrient content were the factors responsible for AMF species richness in the soils. Similar with Khaekhum et al. (2017), found that the number of AM fungal spores in the rhizosphere of eucalyptus was higher soil moisture content (rainy season) and lower in low soil moisture content (dry season). Furthermore, a high level of $\mathrm{P}$ had a negative effect on AM fungal distribution (Rubio et al. 2003; Alguacil et al. 2010). Wang et al. (2009) indicated that increasing the P content significantly reduced the species diversity of AMF. Our study showed no significant difference in spore density across the plantations. However, we found that the species composition of AMF in the rhizosphere of PM plantation was not similar to the other two plantations (Figure 4). Several studies revealed that factors related to the host plant can affect community structure of the AM fungal species (Chaturvedi et al. 2009; Pérez and Urcelay 2009; Torrecillas et al. 2012). Chaturvedi et al. (2009) reported that a high diversity of hosts, such as a natural forest, had a higher diversity of AMF in rhizosphere of the soils than a single host plant. Moreover, Torrecillas et al. (2012) found that different plant families were hosts to different AM fungal communities and that the roots of annual plants had a higher number of AM fungal spores compared to the perennial plant species. In general, the roots of different plants produce different types of organic chemicals and volatile compounds, which could contribute to the activity and affect the life cycles of AMF in a natural ecosystem (Dhar and Mridha 2006). Therefore, further studies are required to select the appropriate AM fungal species which have a positive effect on the growth of $D$. cochinchinensis, $P$. macrocarpus, and X. xylocarpa. The study can also be used in inoculation programs in order to restore AM fungal diversity in degraded lands.

In conclusion, AM fungi could be classified in three genera, which were 3 species of Acaulospora, 7 species of Glomus, and 1 species of Scutellospora. Meanwhile, three species remained unidentified. The DC plantation soils had the highest species diversity index and the lowest in the $\mathrm{XX}$ plantation due to the differences in soil characteristics, including moisture, $\% \mathrm{OM}$, and nutrient concentration. In this study, G. maculosum, G. pustulatum and Unknown sp. 2 were the majority in all three plantations. Moreover, AM fungal communities of three Fabaceous trees species were different. These differences may be due to the different types of organic chemicals and volatile compounds from their roots.

\section{ACKNOWLEDGEMENTS}

This work was financed by the Kasetsart University Research and Development Institute and research fund for supporting assistant researcher from Faculty of Forestry, Kasetsart University, Thailand (OPORA-2015). We would like to sincerely thank the head of Sakaerat silvicultural research station for all kind supports. The manuscript has been thoroughly reviewed with the kind help of Dr. Tushar Andriyas from Center for Material Sciences, Institute of Interdisciplinary Studies, University of Allahabad, India.

\section{REFERENCES}

Alguacil M, Del M, Lozano Z, Campoy MJ, Roldán A. 2010. Phosphorus fertilisation management modifies the biodiversity of AM fungi in a tropical savanna forage system. Soil Biol Biochem 42: 1114-1122.

Bever JD, Morton JB, Antonovics J, Schultz PA. 1996. Host-dependent sporulation and species diversity of arbuscular mycorrhizal fungi in a mown grassland. J Ecol 84: 71-82.

Brundrett MC. 2009. Mycorrhizal associations and other means of nutrition of vascular plants: understanding global diversity of host plants by resolving conflicting information and developing reliable means of diagnosis. Plant Soil 320: 37-77.

Brundrett M, Bougher N, Dell B, Grove T, Malajczuk N. 1996. Working with Mycorrhizas in Forestry and Agriculture. ACIAR Monograph 32. ACIAR, Australia.

Cardoso EJBN, Nogueira MA, Zangaro W. 2017. Importance of mycorrhizae in tropical soils. In: Azevedo JL, Quecine MC (eds). Diversity and Benefits of Microorganisms from the Tropics. Springer International Publishing, Berlin.

Charoenpakdee S, Cherdchai P, Dell B, Lumyong S. 2010. The mycorrhizal status of indigenous arbuscular mycorrhizal fungi of physic nut (Jatropha curcas) in Thailand. Mycosphere 1 (2): 167-181. 
Chaturvedi S, Mehta CM, Singh S and Sharma AK. 2009. Host influences arbuscular mycorrhizal fungal diversity. J Mycol Pl Pathol 39 (1) 124-130.

CITES COP17 Prop.55. 2016. Convention on International Trade in Endangered Species of Wild Fauna and Flora. https: //cites.org/sites/default/files/eng/cop/17/prop/060216/E-CoP17-Prop55 .

Daniels BA, Skipper HD. 1982. Methods for the recovery and quantitative estimation of propagules from soil. In: Schenck NC (ed.). Methods and Principle of Mycorrhizal Research. American Phytopathological Society, USA.

Dhar PP, Mridha MAU. 2006. Biodiversity of arbuscular mycorrhizal fungi in USA: different trees of Madhapur forest, Bangladesh. J For Res 17 (3): 201-205.

Hameed A, Dilfuza E, Abd-Allah EF, Hashem A, Kumar A, Ahmad P. 2014. Salinity stress and arbuscular mycorrhizal symbiosis in plants In: Miransari M (ed). Use of Microbes for the Alleviation of Soil Stresses, Volume 1. Springer Science and Business Media, New York.

Hepper CM. 1984. Isolation and culture of VA mycorrhizal (VAM) fungi. In: Powell CL, Bagyaraj DJ (eds.). VA Mycorrhizae. CRC Press, Florida, USA.

Husband R, Herre EA, Turner SL, Gallery R, Young JPW. 2002. Molecular diversity of arbuscular mycorrhizal fungi and patterns of host association over time and space in a tropical forest. Mol Ecol 11: 2669-2678.

Jenkins A, Bridgland N, Hembery R, Malessa U, Hewitt J, Keong CH. 2012. Background Paper1: Precious Woods: Exploitation of the Finest Timber. Chatman House Workshop: Tackling the Trade in Illegal Precious Woods. 23-24 April 2012. TRAFFIC. http: //www.traffic.org/non-trafficpapers/

Kamo K, Vacharangkura T, Tiyanon S, Viriyabuncha C, Nimpila S, Doangsrisen B. 2002. Plant species diversity in tropical planted forests and implication for Reforestation of forest ecosystems in Sakaerat, northeast Thailand. Japan Agric Res Quart 36 (2): 111-118.

Khaekhum S, Lumyong S, Kuyper TW, Boonlue S. 2017. Species richness and composition of arbuscular mycorrhizal fungi occurring on eucalypt trees (Eucalyptus camaldulensis Dehnh.) in rainy and dry season. Current Research in Environ Appl Mycol 7 (4): 282-292.

Kiers ET, Lovelock CE, Krueger EL, Herre EA. 2000. Differential effects of tropical arbuscular mycorrhizal fungal inocula on root colonization and tree seedling growth: implications for tropical forest diversity. Ecol Lett 3: 106-113.

Krüger M, Krüger C, Walker C, Stockinger H, Schüßler A. 2012. Phylogenetic reference data for systematics and phylotaxonomy of arbuscular mycorrhizal fungi from phylum to species level. New Phytol 193: 970-84.

Latef AAHA, Hashem A, Rasool S, Abd Allah EF, Alqarawi A.A, Egamberdieva D., Jan S, Anjum NA, Ahmad P. 2016. Arbuscular mycorrhizal symbiosis and abiotic stress in plants: a review. J Plant Biol 59: 407-426.

Lee E, Eo J, Ka K, Eom A. 2013. Diversity of arbuscular mycorrhizal fungi and their roles in ecosystems. Mycobiology 41 (3): 121-125.

Magurran AE. 1988. Ecological Diversity and Its Measurement. Princeton University Press, New Jersey.

Marinho F, da Silva IR, Oehl F, Maia LC. 2018. Checklist of arbuscular mycorrhizal fungi in tropical forests. Sydowia 70: 107-127.

Morton JB, Msiska Z. 2010. Phylogenies from genetic and morphological characters do not support a revision of Gigasporaceae (Glomeromycota) into four families and five genera. Mycorrhiza 20 483-496.
Nongkling P, Kayang H. 2017. Soil physicochemical properties and its relationship with AMF spore density under two cropping systems. Curr Res Environ Appl Mycol 7 (1): 33-39.

Oehl F, Sieverding E, Palenzuela J, Ineichen K, Silva GA. 2011. Advances in Glomeromycota taxonomy and classification. IMA Fungus 2: 191-199.

Peck, JE. 2010. Multivariate Analysis for community ecologists: step-bystep using PC-ORD. MjM Software Design, USA.

Pérez M, Urcelay C. 2009. Differential growth response to arbuscular mycorrhizal fungi and plant density in two wild plants belonging to contrasting functional types. Mycorrhiza 19: 517-523.

Pielou, E. 1966. The measurement of diversity in different types of biological collections. J Theor Biol 13: 131-144.

Ponpandian SV, Rose AES. 2017. Status of arbuscular mycorrhizal fungi in tree species from Eastern Ghats of Tamil Nadu, India. Intl J Sci Res 6 (6): 415-422.

Pozo MJ, Jung Sc, López-Ráez JA, Azcón-Aguilar C. 2010. Impact of arbuscular mycorrhizal symbiosis on plant response to biotic stress: the role of plant defence mechanisms. In: Koltai H, Kapulnik Y (eds.). Arbuscular Mycorrhizas: Physiology and Function. Springer Science+Business Media, New York.

Rubio R, Borie F, Schalchli C, Castillo C, Azcón R. 2003. Occurrence and effect of arbuscular mycorrhizal propagules in wheat as affected by the source and amount of phosphorus fertilizer and fungal inoculation. Appl Soil Ecol 23: 245-255.

Schenck NC, Perez Y. 1988. Manual for the Identification of VM mycorrhiza fungi. International Culture Collection of VA Mycorrhizal fungi (INVAM), Florida.

Smith SE, Read DJ. 2008. Mycorrhizal Symbiosis. 3rd ed. Academic, San Diego, CA, USA.

Stürmer SL, Siqueira JO. 2010. Species richness and spore abundance of arbuscular mycorrhizal fungi across distinct land uses in Western Brazilian Amazon. Springer Verlag, Berlin.

Torrecillas E, Alguacil MM, Roldán A. 2012. Host preferences of arbuscular mycorrhizal fungi colonizing annual herbaceous plant species in semiarid Mediterranean prairies. Appl Environ Microbiol 78 (17): 6180-6186

Upadhyaya H, Panda SK, Bhattacharjee MK, Dutta S. 2010. Role of arbuscular mycorrhiza in heavy metal tolerance in plants: prospects for phytoremediation. J Phytol 2 (7): 16-27

Visaratana T, Vhangsisang C, Chernkhuntod C. 2004. Litter production in forest plantation with different age. J Thai For Res 4: 1-48. [Thai]

Visaratana T, Chernkhuntod C, Thai-ngamsuksirikul. 2008. Climatic data of Sakaerat silvicultural research station. J Thai Forestry Research 11: 1-31. (Thai)

Wang MY, Hu LB, Wang WH, Liu ST, Li M, Lui RJ. 2009. Influence of long-term fixed fertilization on diversity of arbuscular mycorrhizal fungi. Pedosphere 19: 663-672.

Washa WBA, Nyomora AMS, Lyaruu HVM. 2012. Improving propagation success of Dalbergia melanoxylon (African blackwood) in Tanzania (I): characterization of mycorrhiza associated with $D$. melanoxylon (African blackwood) in Tanzania. Tanz J Sci 38 (1): 3542.

Weravart N. 2003. Genetic diversity of arbuscular mycorrhizal fungi infected 181 Acacia mangium Willd. [Dissertation]. Suranaree University, Nakorn Ratchasrima, Thailand.

Wulandari D, Saridi, Cheng W, Tawaraya K. 2016. Arbuscular mycorrhizal fungal inoculation improves Albizia saman and Paraserianthes falcataria growth in post-opencast coal mine field in East Kalimantan, Indonesia. For Ecol Manag 376: 67-73.

Zhao ZW, Wang GH, Yang L. 2003. Biodiversity of arbuscular mycorrhizal fungi in tropical rainforests of Xishuangbanna, southwest China. Fungal Divers 13: 233-242. 